\title{
Assessment of Background Radiation and Associated Dose Rates in Soil Samples from Norochcholai in the North Western Coast of Sri Lanka
}

\author{
Thiwanka Weerakkody ${ }^{1}$, Senani Williams ${ }^{2}$, Tania Warnakulasuriya ${ }^{2}$, Shakila Priyadarshanee ${ }^{1}$, \\ Thilaka Attanayaka1, Indrani Dissanayake1, Vajira Waduge', Rajitha Wickremasinghe²
}

${ }^{1}$ Sri Lanka Atomic Energy Board, Wellampitiya, Sri Lanka

${ }^{2}$ Faculty of Medicine, University of Kelaniya, Kelaniya, Sri Lanka

Email: thiwankaweerakkody@gmail.com

How to cite this paper: Weerakkody, T. Williams, S., Warnakulasuriya, T., Priyadarshanee, S., Attanayaka, T., Dissanayake, I., Waduge, V., \& Wickremasinghe, R. (2022). Assessment of Background Radiation and Associated Dose Rates in Soil Samples from Norochcholai in the North Western Coast of Sri Lanka. Journal of Geoscience and Environment Protection, 10, 189-206. https://doi.org/10.4236/gep.2022.101013

Received: December 2, 2021

Accepted: January 25, 2022

Published: January 28, 2022

Copyright $\odot 2022$ by author(s) and Scientific Research Publishing Inc. This work is licensed under the Creative Commons Attribution International License (CC BY 4.0).

http://creativecommons.org/licenses/by/4.0/

\begin{abstract}
This study assesses radiation levels in soil, water and air in the Norochcholai, an area in Sri Lanka closest to the Kundankulam nuclear power plant, India which is situated in the North Western coast. This is important for monitoring radiation hazards and will be useful in case of a nuclear accident. Superficial soil and water samples from 23 locations were analyzed by Gamma spectrometry using HPGe detector. The activity concentrations of Th232, K40, Ra226 and $\mathrm{Pb} 210$ in the soil were $56.0 \mathrm{~Bq} \cdot \mathrm{kg}^{-1}, 96.0 \mathrm{~Bq} \cdot \mathrm{kg}^{-1}, 24.0 \mathrm{~Bq} \cdot \mathrm{kg}^{-1}$ and $27.0 \mathrm{~Bq} \cdot \mathrm{kg}^{-1}$ respectively. Dose rate at $1 \mathrm{~m}$ height was recorded using a survey meter (Automess $6150 \mathrm{AD}$ ). Median dose rate was $0.098 \mu \mathrm{Sv} \cdot \mathrm{h}^{-1}$. The median gamma ray absorbed dose rate was $51.2 \mathrm{nGy} \cdot \mathrm{h}^{-1}$, which is lower than the global average of $57 \mathrm{nGy} \cdot \mathrm{h}^{-1}$. Radium equivalent activity (Raeq) ranged from $30.3 \mathrm{~Bq} / \mathrm{Kg}-458.3$ $\mathrm{Bq} / \mathrm{Kg}$ and only one sample recorded the Raeq $>370 \mathrm{~Bq} / \mathrm{Kg}$ as safe to be used in building materials. External hazardous indices of all the samples were below 1 and the mean annual effective dose was within the safe limit of $1 \mathrm{mSv} / \mathrm{y}$. The health risk of exposure to terrestrial radiation from the soil in the area is minimal. These data could be used as baseline for radiation assessment.
\end{abstract}

\section{Keywords}

Background Radiation, Gamma Spectrometry, Norochcholai, Health Risk, Radiological Indices

\section{Introduction}

Norochcholai in the Puttalam district is situated in the North western coast of 
Sri Lanka. The Kundankulam nuclear power plant in India (very close to Sri Lanka's maritime boundary), is situated $360 \mathrm{~km}$ North of the tip of Tamil Nadu in Southern India; Norochcholai, is the closest area in Sri Lanka to the Kundankulam nuclear power plant situated about $200 \mathrm{~km}$ away. The International Atomic Energy Agency stipulates that "all countries within $300 \mathrm{~km}$ be notified for a general emergency at a large reactor (transnational emergency) as part of emergency planning (IAEA, 2015). In the case of a radiation accident, this area is likely to be affected. This area was chosen for the study as this population was the closest to the Kundankulam nuclear power plant. Therefore, emergency preparedness of this area is very important.

Thorium bearing mineral deposits are commonly found along the coastline of Sri Lanka. Uswetakeiyawa, Kelido beach Kalutara (in the western coast of Sri Lanka) and Pulmoddai (in the eastern coast) regions have been identified as high background radiation areas (Mahawatte \& Fernando, 2013). Kaudupelalla and Raththota areas in Matale district (mid-country) were recently identified as high background radiation areas having radiation levels of $275-303 \mathrm{nSv} \cdot \mathrm{h}^{-1}$ (Sri Lanka Atomic Energy Board, 2018). The largest monazite deposits in Sri Lanka are found in Beruwala, Pulmoddai, Hendala and Kalutara. The average exposure rate obtained from normal background areas of Sri Lanka varies from 0.01 (0.876 $\left.\mathrm{mSv} \cdot \mathrm{y}^{-1}\right)$ to $0.04 \mathrm{mR} \cdot \mathrm{h}^{-1}\left(3.506 \mathrm{mSv} \cdot \mathrm{y}^{-1}\right)$. In areas where background radiation levels are high as in Beruwala, the highest dose rate is approximately $2.25 \mathrm{mR} \cdot \mathrm{h}^{-1}$ (197.23 mSv $\cdot \mathrm{y}^{-1}, 22{ }^{*}$ natural radiation level).

People living in mountainous areas receive a higher dose of radiation due to cosmic radiation from the sun which interacts with the atmosphere and produces secondary cosmic rays including electromagnetic radiation. According to world nuclear association data, the annual human exposure to ionizing radiation is $2.4 \mathrm{mSv}$ per year.

In areas where extremely high background radiation levels are detected in the world, such as in Brazil, Kerala (India) and Ramsar (Iran), the values are 250 $\mathrm{mSv} /$ year, $17 \mathrm{mSv}$ per year and $450 \mathrm{mSv}$ per year, respectively (Bavarnegin, Moghaddam, \& Fathabadi, 2013). The highest level of natural background radiation of $800 \mathrm{mSv} / \mathrm{yr}$. was recorded in an uninhabited Brazilian beach.

The annual effective dose around the population living in Kundankulam area adjacent to a nuclear power plant in southern India is $0.149 \mathrm{mSv} / \mathrm{year}$ and the indoor gamma radiation has been calculated as $1.18 \mathrm{mSv} / \mathrm{year}$. The effective dose rate varied from $0.05-22.23 \mathrm{mSv} /$ year (Subramanian, Jeyapandian, Brahmanandhan, \& Khanna, 2009). An individual living in the vicinity of a coal power station may be exposed to a maximum dose of up to 23 milirem (0.23 $\mathrm{mSv}$ ) per year due to fly ash emissions (Atomic Energy Authority, Sri Lanka, 1988).

There are four major groups of radionuclides based on their origin (Malanca, Gaidolfi, Pessina, \& Dallara, 1996): cosmic ray produced nuclides e.g. ${ }^{7} \mathrm{Be}$ and ${ }^{14} \mathrm{C}$; artificially produced radionuclides e.g. ${ }^{137} \mathrm{Cs}$ and ${ }^{90} \mathrm{Sr}$; primordial isotopes 
e.g. ${ }^{238} \mathrm{U},{ }^{40} \mathrm{~K}$ and ${ }^{232} \mathrm{Th}$; and natural decay products e.g. ${ }^{226} \mathrm{Ra}$, and ${ }^{222} \mathrm{Rn}$. There are three naturally occurring radioactive decay chains $\left({ }^{238} \mathrm{U},{ }^{235} \mathrm{U}\right.$ and $\left.{ }^{232} \mathrm{Th}\right)$ that end up in stable $\mathrm{Pb}$ isotopes. The major source of radiation exposure to humans and all organisms is mainly caused by activity concentrations of the three major radionuclides such as Ra226, Th232, and K40. These radionuclides in soils are not evenly distributed and vary from region to region (Bozkurt, Yorulmaz, Kam, Karahan, \& Osmanlioglu, 2007) (Tzortzis, Svoukis, \& Tsertos, 2001). Knowledge of the activity concentrations of these radionuclides is important for radiation protection measurements (Rani \& Singh, 2005) as elevated levels of radioactivity concentration levels are harmful to human health.

This study assessed background radiation in soil, water and air in Norochcholai in the North Western coast of Sri Lanka.

\section{Method}

The study was conducted in the Norochcholai grama niladhari area (smallest administrative area) situated in the Kalpitiya Divisional Secretariat of the Puttalam district of Sri Lanka. The population of the GN area was 7069 in 2012 and consisted of 3574 males and 3495 females (Department of Census and Statistics, 2012). Norochcholai, in the Puttalam district was chosen for the study as this population is the closest to the Kundankulam nuclear power plant in India (approximately $200 \mathrm{~km}$ away from Kundankulam). Sampling locations are shown in Figure 1.

The study participants were randomly selected from the most recent voters list maintained by the Grama Niladhari officer of the area. Measurements of background radiation and soil and drinking water samples for gamma spectrometry were obtained from homesteads of study participants. Twenty-three soil samples and twenty-three water samples were collected for analysis.

\subsection{Collection of Soil Samples}

Top $2 \mathrm{~cm}$ of soil was scraped off from a $1 \mathrm{~m}^{2}$ area and $1 \mathrm{~kg}$ of soil was taken from near the front door of homesteads of selected participants. The samples were immediately brought to the laboratory for analysis in sealed dark plastic bags. Samples were homogenized by hand mixing and allowed to air dry. Then the samples were oven dried (400C) overnight (24 hours) to reduce moisture. Dried samples were sieved by using $2 \mathrm{~mm}$ sieve and stored in G1 geometry (8.4 $\mathrm{cm} \times 2.9 \mathrm{~cm}$ radon impermeable plastic containers). Soil samples were prepared for Gamma spectroscopic analysis. Samples were hermetically sealed and stored to achieve secular equilibrium for three weeks (seven half-lives of Rn222, half-life of Rn222 = 3.82 days) before analysis. Their respective net weights were measured and recorded (IAEA, Measurement of Radionuclides, 1989).

One liter of drinking water samples from 23 locations were collected in one-liter plastic bottles. They were shaken well, filtered and stored in G2 geometry $(11.8 \mathrm{~cm} \times 10.4 \mathrm{~cm}$, radon impermeable plastic containers $)$ in the laboratory. 
The samples were sealed and the sealed containers left for 22 days before counting by gamma spectrometry to ensure that the daughter products of Ra226 achieve equilibrium with their respective parent radionuclides. Their respective net weights were measured and recorded.
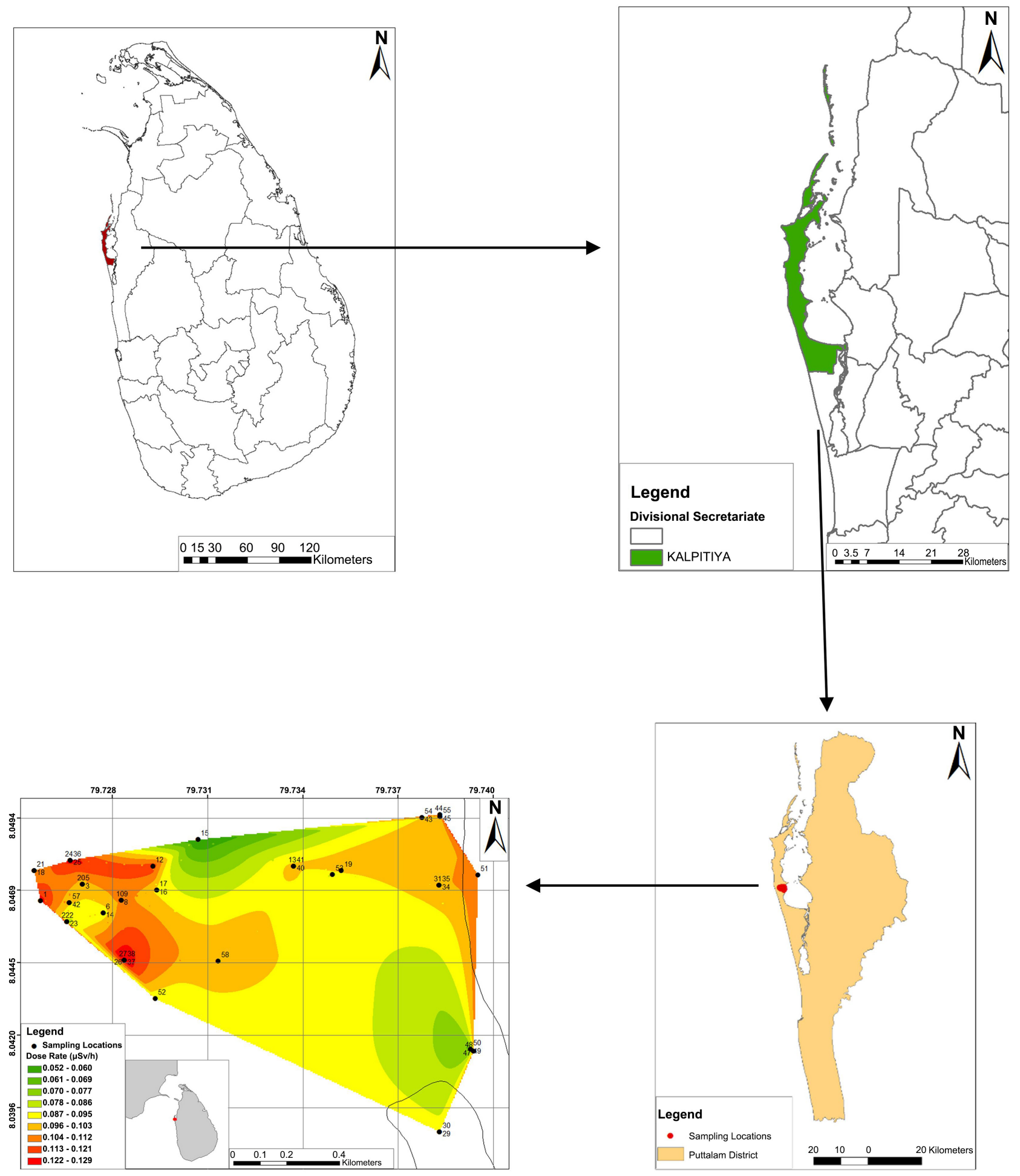

(a) 


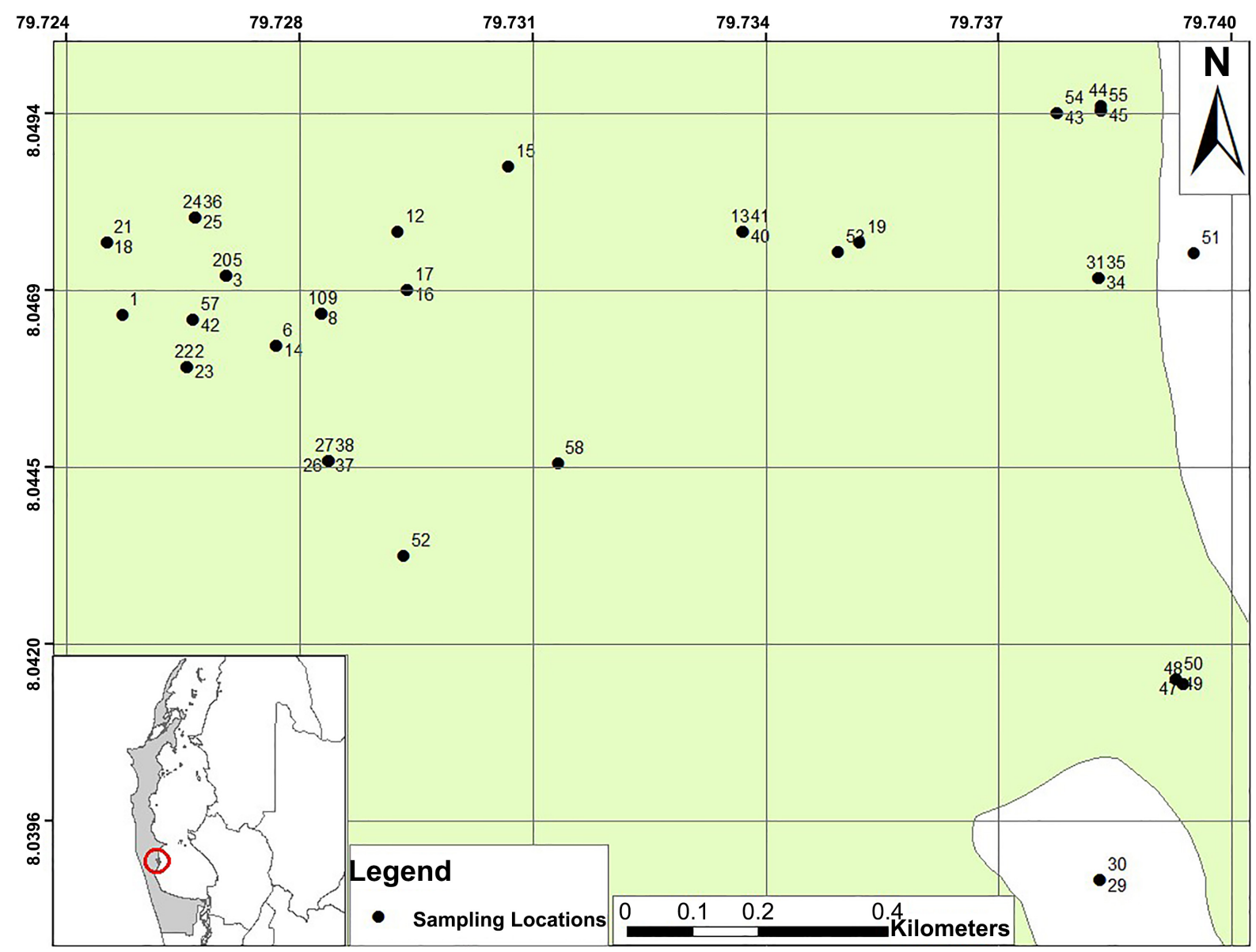

(b)

Figure 1. (a) Map of sampling locations, Norochcholai, Sri Lanka. The sampling locations of the Norochcholai area are marked as black dots and the numbers represent personal identification numbers of the study participants. (b) Map of sampling locations, Norochcholai, Sri Lanka. The sampling locations of the Norochcholai area are marked as black dots and the numbers represent personal identification numbers of the study participants.

\subsection{Sample Analysis}

The specific activities of the radionuclides ${ }^{40} \mathrm{~K},{ }^{226} \mathrm{Ra},{ }^{232} \mathrm{Th},{ }^{210} \mathrm{~Pb}$ in the collected samples were measured in the Hyper-pure Germanium detector (HPGe) (model: Gx3020) with a relative efficiency of $32.6 \%$ and an energy resolution of $1.84 \mathrm{keV}$ at $1.3 \mathrm{MeV}$ gamma line of $60 \mathrm{Co}$. The efficiency of the detector is specified as the photopeak efficiency relative to that of standard. The resolution of the detector is specified as the full width (in $\mathrm{keV}$ ) at half maximum (FWHM) of the full energy peak of the $1.33 \mathrm{MeV}$ peak of the $60 \mathrm{Co}$ as between $1.8 \mathrm{keV}$ and $2.2 \mathrm{keV}$ (IAEA, Measurement of Radionuclides, 1989). High voltage was supplied to the detector $(1500-5000 \mathrm{~V})$. The detector was shielded by a lead shield of $11 \mathrm{~cm}$ thickness. The inner surface of the shield was covered with a $2 \mathrm{~mm}$ thick $\mathrm{Cu}$ sheet. Digital Spectrum Analyzer 1000 (DSA1000) is responsible for spectra accumulation and has 8192 channels. Soil 6 was used as a reference material for detector calibration. Relevant spectra were analyzed using the GENIE 2000 data acquisition Canberra software. The counting time was 72,000 seconds. The region under the 
peaks corresponding to $1.46 \mathrm{MeV}$ for $\mathrm{K} 40,0.609 \mathrm{MeV}$ for Ra226, $0.238 \mathrm{MeV}$ for Th232 and $0.0465 \mathrm{MeV}$ for Pb210 were used. The Minimum Detectable Activity (MDA) of the radionuclides was determined from the background radiation spectrum obtained for the same counting time. Activity concentration of each of the radionuclides was calculated (Miah, Miah, Kamal, Chowdhury, \& Rahmatullah, 2012). Peak areas of gamma spectra were analyzed by GENIE 2000 computer software.

Background radiation levels in homes of all participants were monitored using a calibrated Auto mess dose rate meter 6150AD (Automation and measurements GMBH, German registration number 30355528).

\subsection{Estimation of Dose Rates and Calculation of Radiological Indices}

\subsubsection{Radium Equivalent Activity (Raeq)}

The Radium equivalent activity (Raeq) is a common radiological index that presents activity levels of Ra226, Th232 and K40 as a single quantity and this was calculated for all the soil samples (Warnakulasuriya et al., 2020; Raghu, Harikrishnan, Chandrasekaran, Govardhanan, \& Ravisankar, 2015).

\subsubsection{Absorbed Dose Rate (D)}

Absorbed dose rate in air at $1 \mathrm{~m}$ above ground level depends on the concentration of radionuclides in soil. The major part of gamma radiation comes from terrestrial radionuclides (Dhawal, Kulkarni, \& Pawar, 2013). The absorbed dose rates were calculated for all the soil samples (Warnakulasuriya et al., 2020; Vasconcelos et al., 2011).

\subsubsection{Annual Effective Dose}

Biological systems are always affected by ionizing radiation that depends on factors such as the time of exposure, place of exposure, population exposed etc. In most of the cases the risk appears to be higher outdoors than indoors (Ndontchueng, Nguelem, Simo, Njinga, \& Joël, 2014). The Annual Effective Dose is calculated assuming that a person spends 24 hours day, 365 days a year at the location where the samples were collected. Annual effective doses were calculated for all the samples (UNSCEAR, 2000; Warnakulasuriya et al., 2020).

\subsubsection{External Hazard Index (Hex)}

The external hazard index is a criterion to estimate the radiological suitability of a material. Indoor radiation is a result of external exposure of gamma radiation in construction material (Lu \& Zhang, 2006). Hex was calculated for all the soil samples (Warnakulasuriya et al., 2020).

\subsubsection{Criteria Formula (CF)}

Criteria formula is useful to check whether the soil in the area can be used for building construction. The maximum recommended value for criteria formula is 1. By evaluating the annual external radiation dose inside a building constructed 
of building materials with Raeq $=370 \mathrm{~Bq} / \mathrm{kg}$ a value of $1.5 \mathrm{mGy}$ was obtained by Krieger (Krieger, 1981). By considering a wall of finite thickness, presence of windows and doors applying a weighing factor of 0.7 the authors later corrected their calculations (Krieger, 1981). This formula can be mathematically expressed as (Raghu, Harikrishnan, Chandrasekaran, Govardhanan, \& Ravisankar, 2015)

$$
\mathrm{CF}=\mathrm{ARa} / 740+\mathrm{ATh} / 520+\mathrm{AK} / 9620
$$

(Raghu, Harikrishnan, Chandrasekaran, Govardhanan, \& Ravisankar, 2015)

Where, ARa, ATh, AKare activity concentrations of ${ }^{226} \mathrm{Ra},{ }^{232} \mathrm{Th}$, and ${ }^{40} \mathrm{~K}$, respectively, in building materials $(\mathrm{Bq} / \mathrm{kg})$.

\subsubsection{Representative Gamma Index (I $\gamma r$ ) (Gamma Radiation Hazard Index)}

The gamma radiation hazard levels (Nuclear energy Agency organization for economic co-operation and development, 1979) were calculated (Warnakulasuriya et al., 2020).

\subsubsection{Excess Lifetime Cancer Risk (ELCR)}

Excess lifetime cancer risk (ELCR) was calculated as

$$
\mathrm{ELCR} \times 10^{-3}=\mathrm{AEDE} \times \mathrm{DL} \times \mathrm{RF}
$$

Where, AEDE-Annual effective dose equivalent $\left(\mathrm{mSv} \cdot \mathrm{y}^{-1}\right), \mathrm{DL}$ - The duration of life/expectancy (75 years) (World Health Organization, 2016a), RF (risk factor) is the fatal cancer risk per Sv $\left(0.05 \mathrm{~Sv}^{-1}\right)$. (ICRP 60 uses 0.05 as the risk factor value for the public for stochastic effects of low dose radiation) (Cousins, Boice Jr., Cooper, Lee, \& Lochard, 2018).

\subsubsection{Annual Gonadal Equivalent Dose (AGED)}

The annual gonadal equivalent dose (AGED) was calculated for all the samples (Warnakulasuriya et al., 2020).

\subsubsection{Activity Utilization Index (AUI)}

The Activity Utilization Index (AUI) was calculated as

$$
\mathrm{AUI}=\mathrm{ARa} / 50 \mathrm{FRa}+\mathrm{ATh} / 50 \mathrm{FTh}+\mathrm{AK} / 500 \mathrm{FK}
$$

(UNSCEAR, 2012)

Where, ARa, ATh, and AK are activity concentrations of $\mathrm{Ra}$, Th and $\mathrm{K}$, respectively.

FRa, FTh, and FK are the fractional contributions of $\mathrm{Ra}$, Th and $\mathrm{K}$, respectively, to the overall dose level in air attributable to gamma radiation from these radionuclides. It was assumed that $\mathrm{FRa}=0.462, \mathrm{FTh}=0.604$, and $\mathrm{FK}=0.041$. Hence,

$$
\mathrm{AUI}=0.462 \mathrm{ARa} / 50+0.604 \mathrm{ATh} / 50+0.041 \mathrm{AK} / 500
$$

(UNSCEAR, 2012).

\subsection{Mapping and Data Analysis}

The coordinates of the homes of all participants were obtained using GPS monitors. ArcView GIS software was used for mapping and spatial analysis. 
Activity concentrations of radionuclides and dose rates or background radiation measurements were not normally distributed. Therefore, nonparametric tests were used. To check the association between activities of different radionuclides the Spearman rank correlation coefficient was used. A $p$-value $<0.05$ was considered as significant.

\section{Results and Discussion}

Radioactivity was not detected in any of the water samples. Activity concentrations of radionuclides (measured by gamma spectrometry) and the dose rates measured by the survey meter and their logarithmic transformations were not normally distributed $(p<0.001)$. Table 1 shows the activity concentrations of different Naturally Occurring Radioactive Materials (NORMs) in soil samples of Norochcholai area (Figure 4). The typical world values for activity concentrations of ${ }^{232} \mathrm{Th},{ }^{226} \mathrm{Ra}$ and ${ }^{40} \mathrm{~K}$ are $30 \mathrm{~Bq} / \mathrm{kg}, 35 \mathrm{~Bq} / \mathrm{kg}$, and $400 \mathrm{~Bq} / \mathrm{kg}$, respectively (Vasconcelos et al., 2011). The mean activity concentration of ${ }^{232} \mathrm{Th}$ of $69.4 \mathrm{~Bq} / \mathrm{kg}$ is higher than the world's average but the mean activity concentrations of ${ }^{226} \mathrm{Ra}$ $(28.8 \mathrm{~Bq} / \mathrm{kg})$ and ${ }^{40} \mathrm{~K}(108.8 \mathrm{~Bq} / \mathrm{kg})$ are lower than the typical world values. In Kundankulam, India, the mean activity concentrations of ${ }^{232} \mathrm{Th}$ and ${ }^{40} \mathrm{~K}$ have been reported as $148.1 \mathrm{~Bq} / \mathrm{kg}$ and $238.8 \mathrm{~Bq} / \mathrm{kg}$, respectively (Wesley, 2012), both of which are higher than what we found in Norochcholai. Natural environmental radiation of an area mainly depends on the geographical and geological conditions of the region (Florou \& Kritidis, 1992). In Sri Lanka, the maximum activity concentration of ${ }^{232} \mathrm{Th}(19,600 \mathrm{~Bq} / \mathrm{kg})$ was recorded along the coastal strip from Crow Island to Beruwala, a part of the south western coast of Sri Lanka (Withanage \& Mahawatte, 2013). The activity concentration of the coastal strip from Uswetakeyyawa to Chillaw (west coast of Sri Lanka) was recorded as $6257 \mathrm{~Bq} \cdot \mathrm{kg}^{-1}$ (Mahawatte \& Fernando, 2013). In some regions of Maharashtra, India, Thorium activity concentration varied between $30.08 \pm 0.14$ and $96.18 \pm 31 \mathrm{~Bq} / \mathrm{kg}$ which is higher than the global average (Dhawal, Kulkarni, \& Pawar, 2013). The study of radioactivity levels in beach sand from Hambantota to Dondra, Sri Lanka reported that the concentrations of ${ }^{232} \mathrm{Th}$ and ${ }^{40} \mathrm{~K}$ that ranged from $1407-10,752.20$, and 54.5 - $852.57 \mathrm{~Bq} \cdot \mathrm{kg}^{-1}$, respectively (Bandara \& Mahawatte, 2015).

Table 1. Activity concentrations of ${ }^{40} \mathrm{~K},{ }^{226} \mathrm{Ra},{ }^{210} \mathrm{~Pb}$ and ${ }^{232} \mathrm{Th}$ in soil samples.

\begin{tabular}{cccccc}
\hline & ${ }^{232} \mathrm{Th}(\mathrm{Bq} / \mathrm{kg})$ & ${ }^{226} \mathrm{Ra}(\mathrm{Bq} / \mathrm{kg})$ & ${ }^{210} \mathrm{~Pb}(\mathrm{~Bq} / \mathrm{kg})$ & ${ }^{40} \mathrm{~K}(\mathrm{~Bq} / \mathrm{kg})$ & $\begin{array}{c}\text { Dose Rate } \\
\left(\mu \mathrm{Sv} \cdot \mathrm{h}^{-1}\right)\end{array}$ \\
\hline Median & 56 & 24 & 27 & 96 & 0.10 \\
Minimum & 16 & 0.7 & 13 & 62.5 & 0.05 \\
Maximum & 256 & 83 & 81 & 294 & 0.13 \\
$25^{\text {th }}$ percentile & 32 & 14 & 23 & 82 & 0.09 \\
$75^{\text {th }}$ percentile & 89 & 40 & 43 & 108 & 0.11 \\
Mean & 69.4 & 28.8 & 34.2 & 108.8 & 0.1 \\
\hline
\end{tabular}


Spearman correlation coefficients were used to assess the correlation between activity concentrations of radionuclides. There was a significant positive correlation between radioactivity concentrations of ${ }^{226} \mathrm{Ra}$ and ${ }^{232} \mathrm{Th}$, and ${ }^{232} \mathrm{Th}$ and ${ }^{210} \mathrm{~Pb}$ (Figure 2 and Figure 3).

${ }^{40} \mathrm{~K}$ isotope contributes most activity (Table 1 ) followed by ${ }^{232} \mathrm{Th},{ }^{226} \mathrm{Ra}$ and ${ }^{210} \mathrm{~Pb}$. The activity concentrations of different radionuclides are scattered in different locations and is not uniform. Median activity concentration of ${ }^{210} \mathrm{~Pb}$ (daughter of the ${ }^{238} \mathrm{U}$ decay series) was similar to the median activity concentration of ${ }^{226} \mathrm{Ra}$ (beginning of the Uranium decay chain). This indicates that the radionuclides are in secular equilibrium (Vasconcelos et al., 2011) (Figure 4).

\section{Estimation of Dose Rates and Calculation of Radiological Indices}

According to world standards, the maximal admissible level for Radium equivalent activity and the recommended maximum value for building materials used in homes and industries is $370 \mathrm{~Bq} / \mathrm{kg}$ (UNSCEAR, 2000; NEA, 1979). The mean radium equivalent activity of the soil samples of Norochcholai was lower than the world's average. Only one sample exceeded the safe limit (458.397 Bq/kg). Hence, soil from this area does not pose any radiological hazard when used for construction purposes. Mahawatte and Fernando reported that more than $50 \%$ of samples from coastal strip from Uswetakeyyawa to Chilaw in the West Coast of Sri Lanka had radium equivalent activity concentrations exceeding the safe

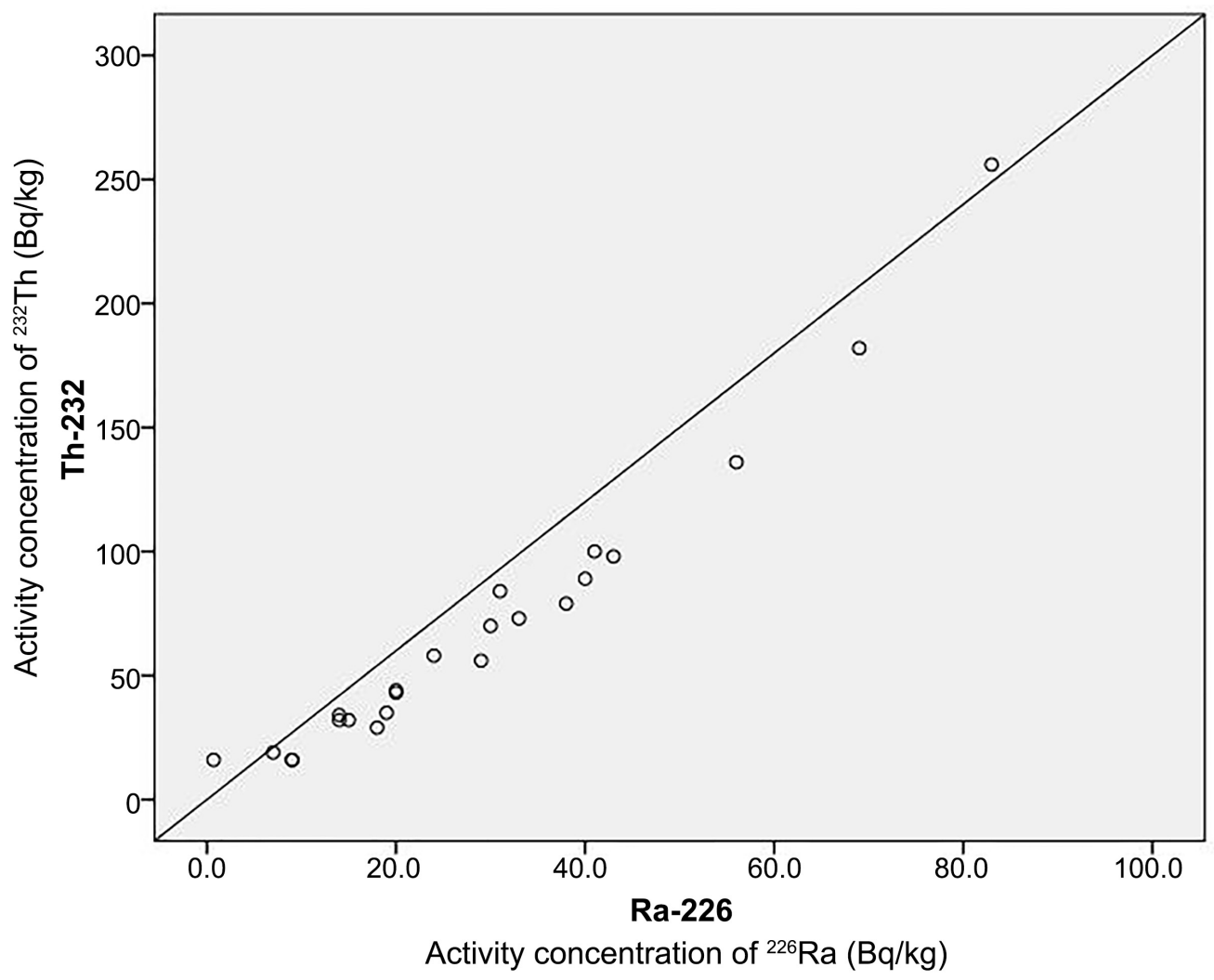

Figure 2. Correlation between activity concentrations (in Bq/kg) of ${ }^{232} \mathrm{Th}$ and ${ }^{226} \mathrm{Ra}$ radionuclides. 


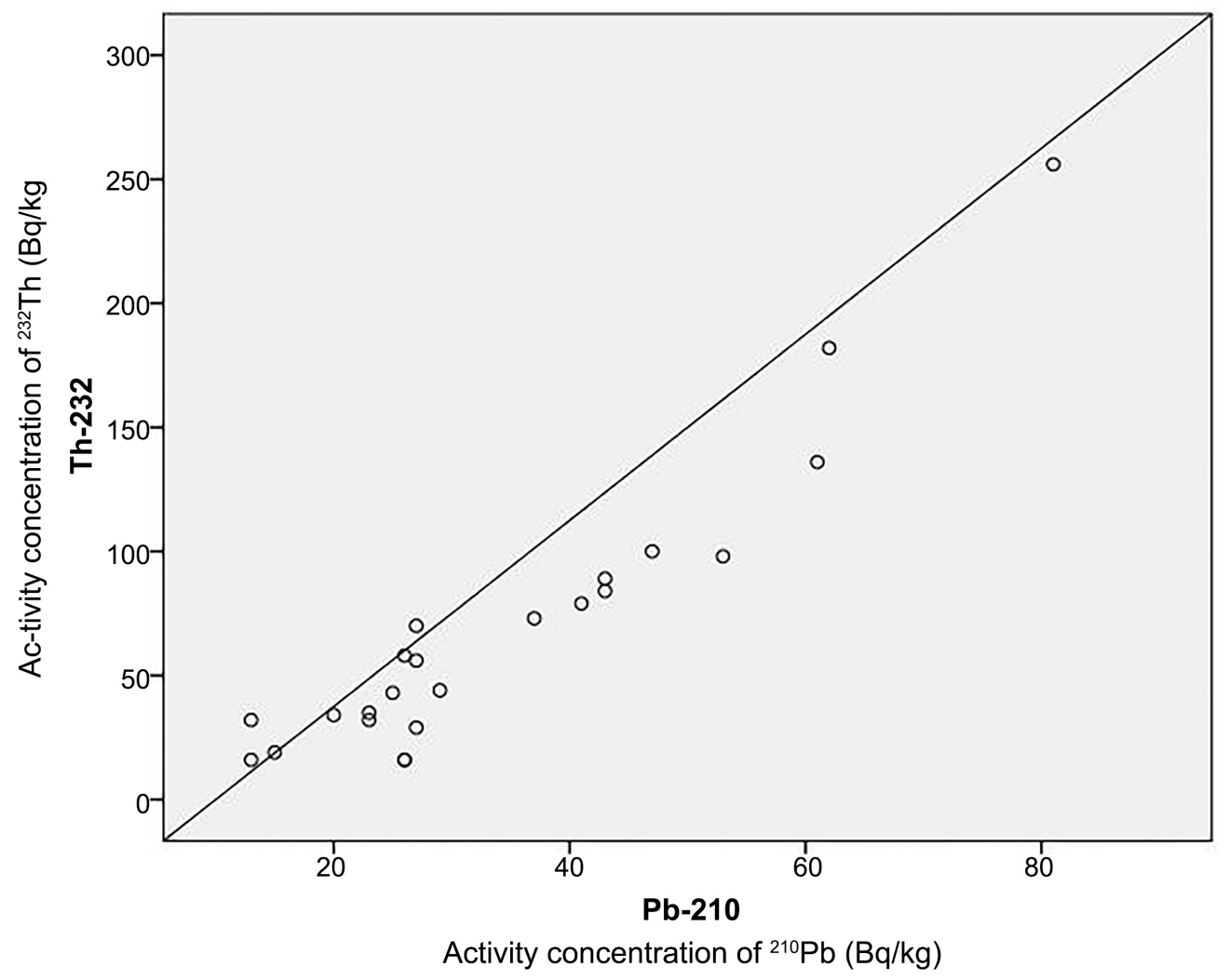

Figure 3. Correlation between activity concentrations (in $\mathrm{Bq} / \mathrm{kg}$ ) of ${ }^{232} \mathrm{Th}$ and ${ }^{210} \mathrm{~Pb}$ radionuclides.

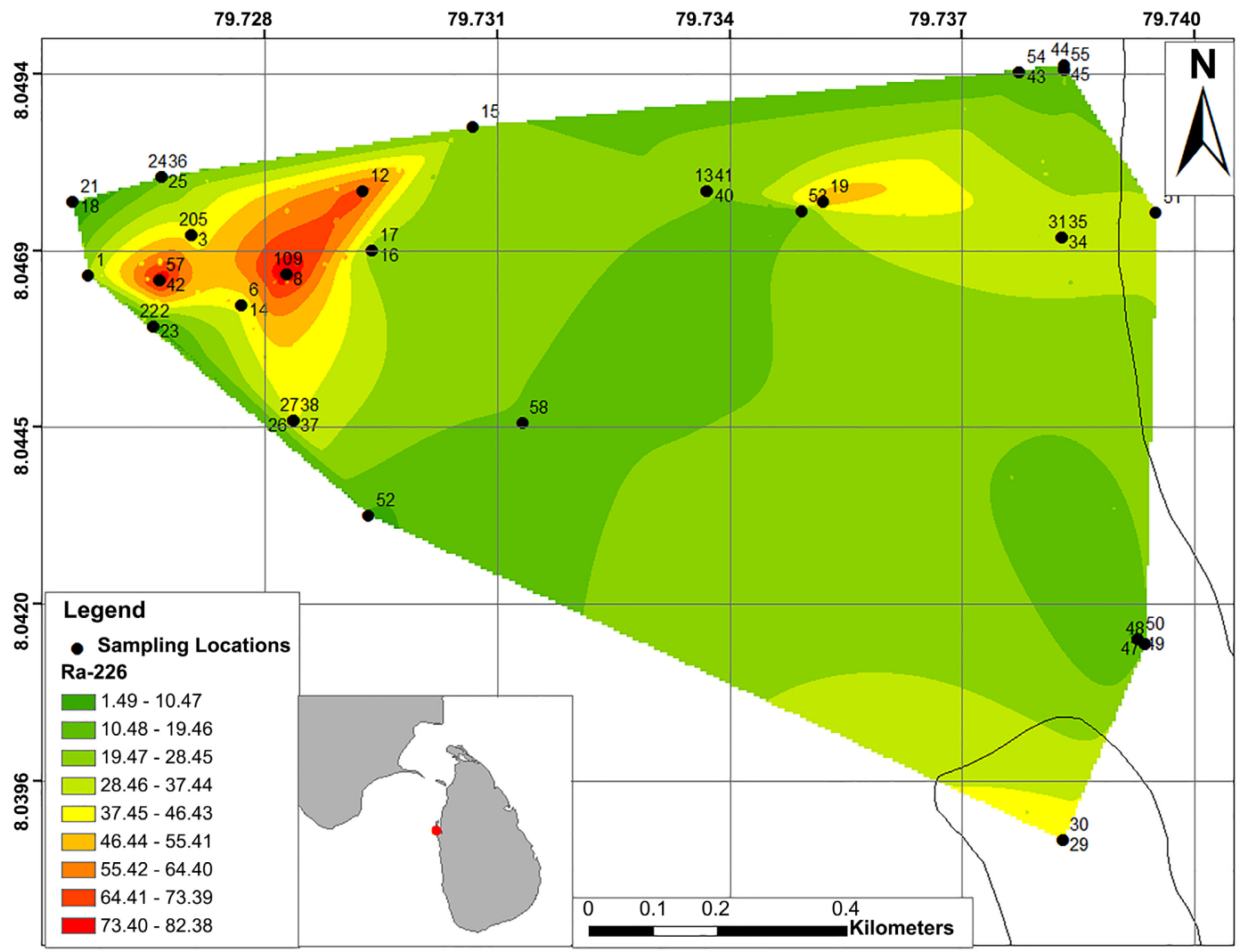

(a) 
T. Weerakkody et al.

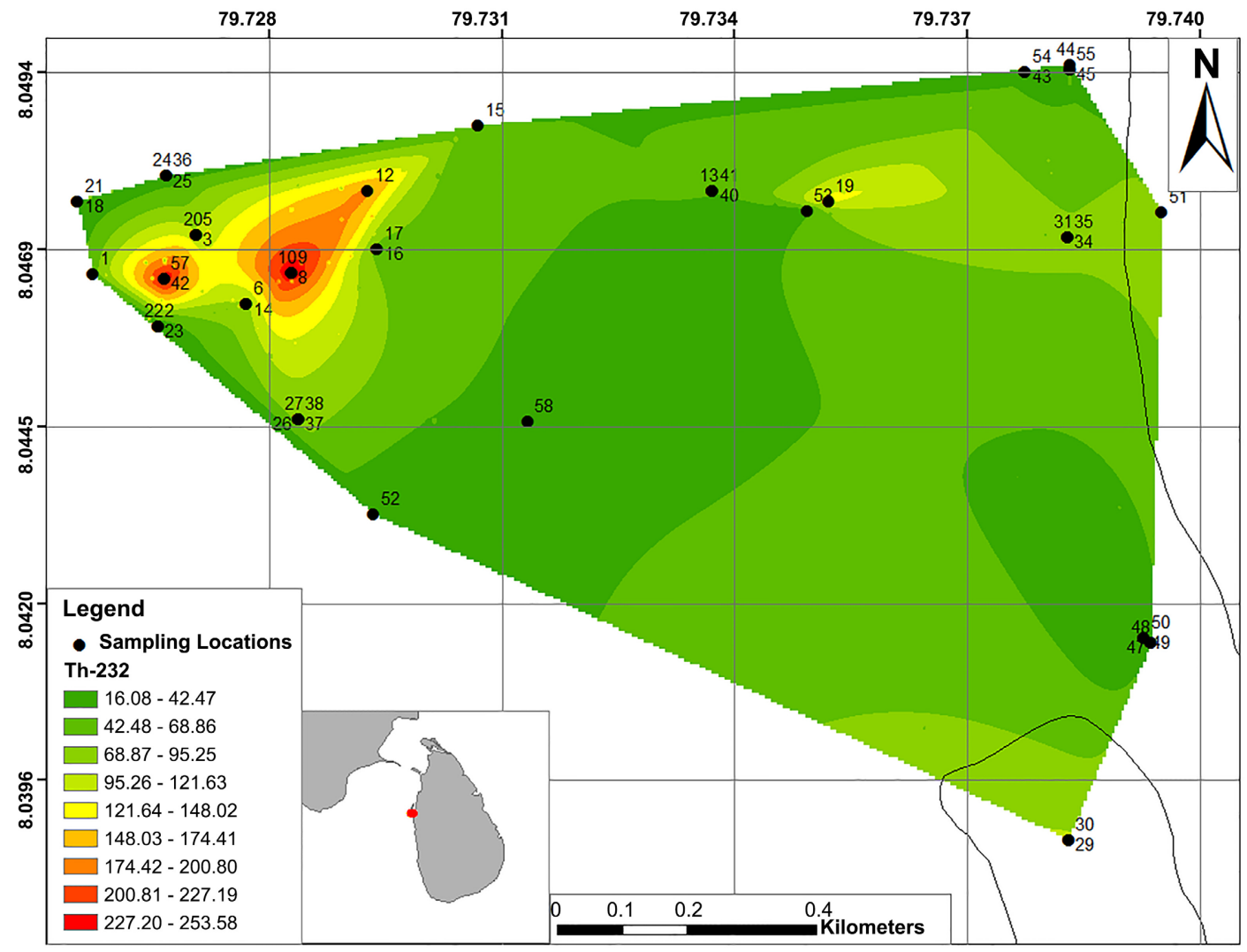

(b)

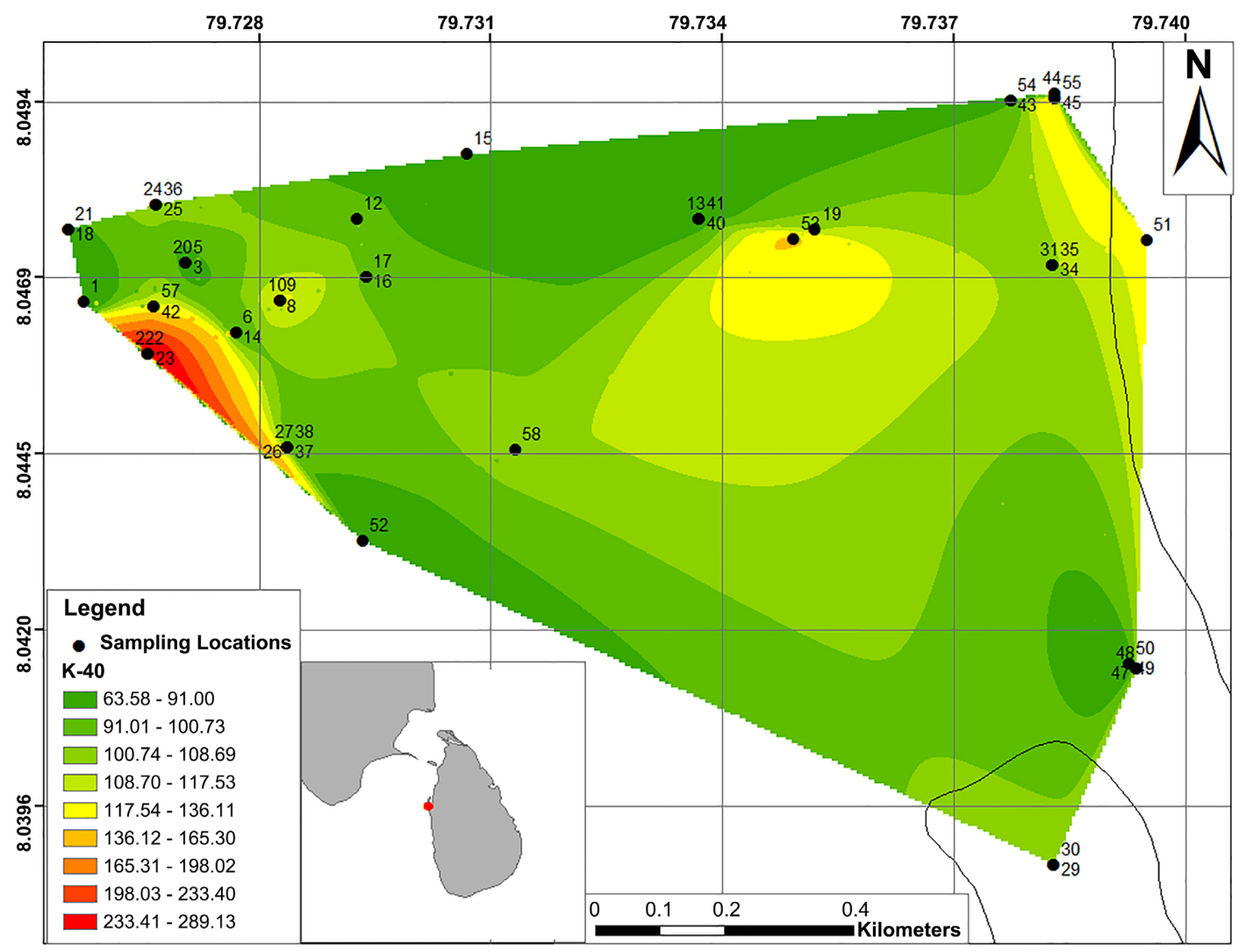

(c) 


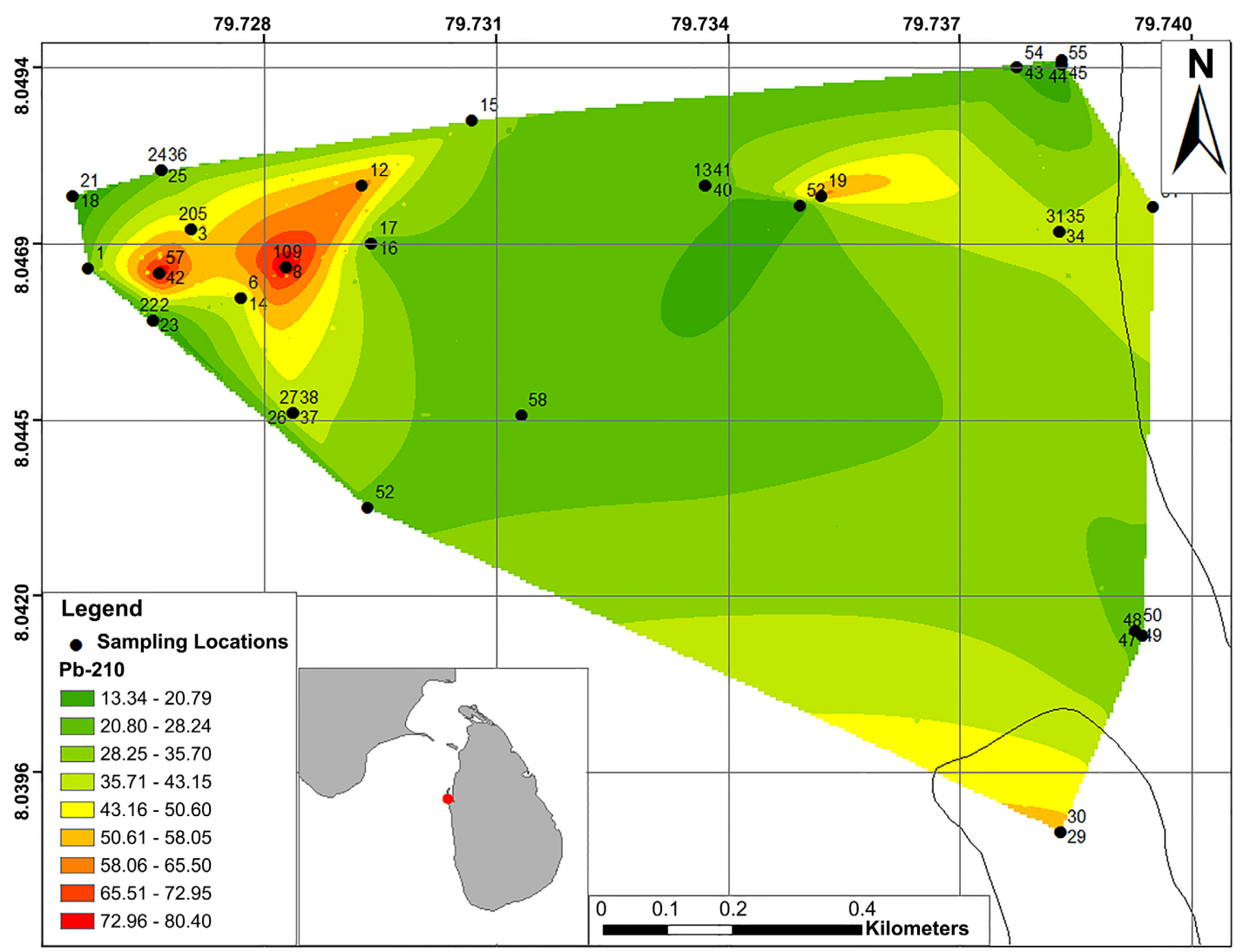

(d)

Figure 4. Interpolation maps of activity concentrations of different radionuclides (a-226Ra, b-232Th, c-40K, $\mathrm{d}-210 \mathrm{~Pb}$, respectively) in Norochcholai area. The sampling locations of the area are marked as black dots and the numbers represent personal identification numbers of the study participants

limit of $370 \mathrm{~Bq} \cdot \mathrm{kg}^{-1}$ (Mahawatte \& Fernando, 2013).

The global average of the absorbed dose rate is $57 \mathrm{nGy} \cdot \mathrm{h}^{-1}$ (UNSCEAR, 2000; European Commission, 1999). The absorbed dose rates due to Th232, K40, Ra226 in soil samples varied between $13.9 \mathrm{nGy} \cdot \mathrm{h}^{-1}$ and $202.8 \mathrm{nGy} \cdot \mathrm{h}^{-1}$ with a median of $51.2 \mathrm{nGy} \cdot \mathrm{h}^{-1}$ which is lower than the global average of $57 \mathrm{nGy} \cdot \mathrm{h}^{-1}$ (UNSCEAR, 2000; European Commission, 1999). Mahawatte and Fernando reported that the calculated external absorbed dose rate at one meter aboveground in the coastal strip from Uswetakeyyawa to Chilaw in the West Coast of Sri Lanka ranged from 5 - $4567 \mathrm{nGy} \cdot \mathrm{h}^{-1}$ which was higher than the world average (give reference). A recent study on terrestrial background radiation conducted in South Konkan, Maharashtra, India reported that the calculated average absorbed dose rate in air was $66.8 \mathrm{nGy} \cdot \mathrm{h}^{-1}$, exceeding the world's average (Dhawal, et al., 2013). A study of the radiological doses and hazard indices in soil samples from an area of Iraq reported that the average absorbed gamma ray dose rate was $90.83 \pm 2.00 \mathrm{nGy} / \mathrm{h}$ which was higher than the world's average (Al-Kaabi \& Al-Shimary, 2015). Background radiation level of the study area varied between $0.05 \mu \mathrm{Svh}^{-1}$ and $0.13 \mu \mathrm{Svh}^{-1}$ (Figure 5 and Table 1 ). The absorbed dose rate was not correlated with the background radiation levels $(p=0.727)$. 


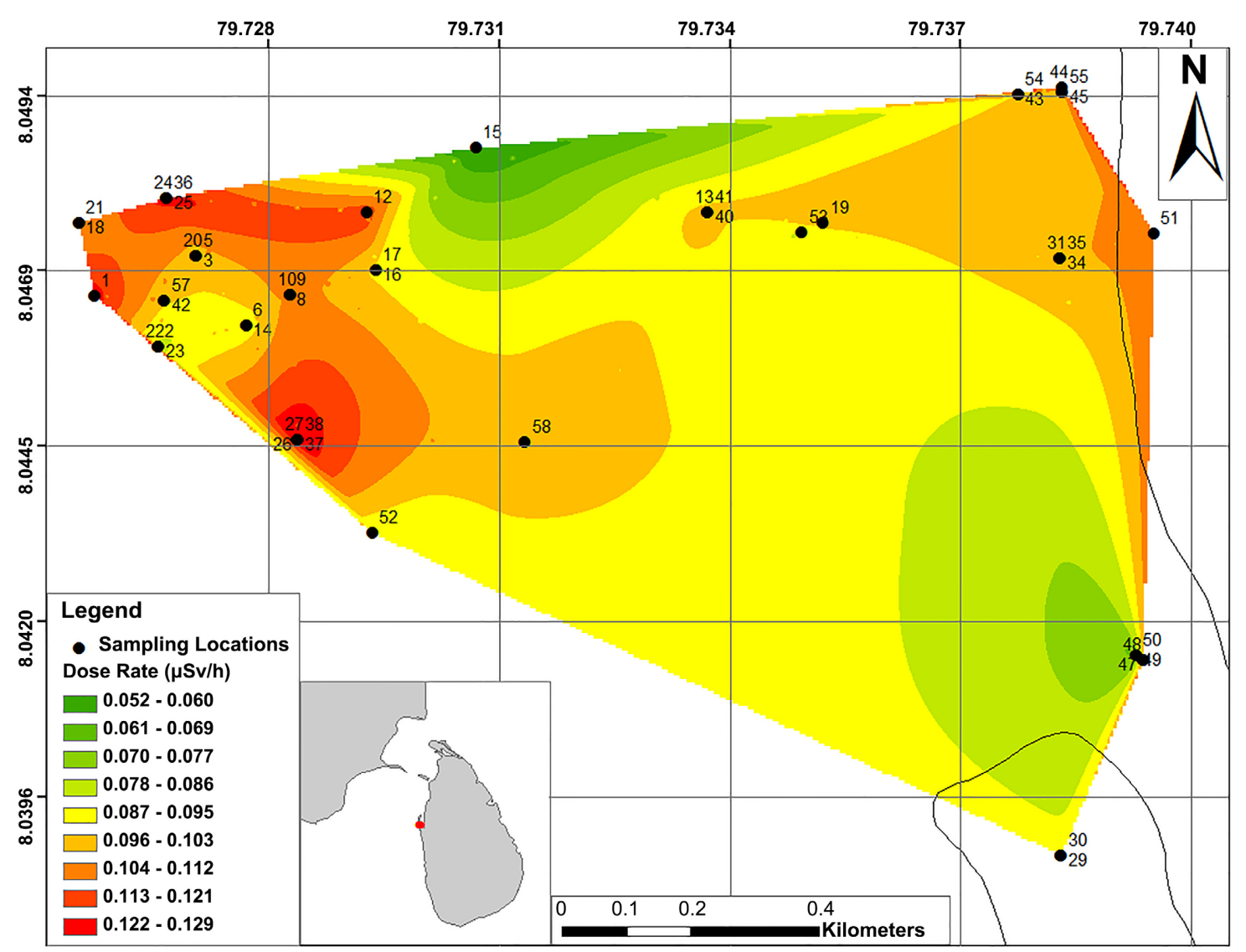

Figure 5. Interpolation map of background radiation (in $\mu \mathrm{Sv} \cdot \mathrm{h}^{-1}$ ) in Norochcholai area. The sampling locations of the Norochcholai area are marked as black dots.

The safe limit of the International Commission on Radiological Protection (ICRP) guidelines for annual effective dose is $1 \mathrm{mSv} \cdot \mathrm{y}^{-1}$ (ICRP, 1977). In our study area, the median annual effective dose was $0.062 \mathrm{mSv} \cdot \mathrm{y}^{-1}$ and the maximum annual effective dose was $0.24 \mathrm{mSv} \cdot \mathrm{y}^{-1}$ (Table 2). The annual effective dose in Kundankulam area of India was reported to be $0.993 \mathrm{mSv} \cdot \mathrm{y}^{-1}$ (Wesley, 2012), higher than the annual effective dose in Norochcholai area. In Maharashtra, India the effective dose rate ranged from $0.27 \mathrm{mSv} \cdot \mathrm{y}^{-1}$ to $0.85 \mathrm{mSv} \cdot \mathrm{y}^{-1}$ (Dhawal et al., 2013) and dose rates were less than the permissable limit. A recent study of radioactivity of beach sand in the North western coast of Sri Lanka (along the coastal strip from Crow Island to Beruwala) reported an effective annual dose ranging from $0.004-16.8 \mathrm{mSv} \cdot \mathrm{y}^{-1}$, exceeding the average worldwide exposure (Withanage et al., 2013).

The median value of the external radiation hazard index is 0.30 which is less than 1. Hence, the area is safe for human habitation (Miah, Miah, Kamal, Chowdhury, \& Rahmatullah, 2012). A recent terrestrial background radiation study in Maharashtra, India revealed that the external hazard index varied from $0.22-0.67$ which was below the recommended limit of 1 (Dhawal et al., 2013). In Tamil Nadu, India, it was recorded as 0.405 (Raghu, Harikrishnan, Chandrasekaran, Govardhanan, \& Ravisankar, 2015). Pulmoddai area located in the Eastern 
Table 2. Radium equivalent activity, absorbed dose rate, annual effective dose, external radiation hazardous index and criteria formula of soil samples.

\begin{tabular}{lcccc}
\hline \multicolumn{1}{c}{ Radiological indices } & Median & Maximum & Minimum & $\begin{array}{c}\text { Typical } \\
\text { World Value }\end{array}$ \\
\hline Radium Equivalent Activity $\left(\mathrm{Ra}_{\mathrm{eq}}\right) \mathrm{Bq} / \mathrm{kg}$ & 114.563 & 458.300 & 30.300 & $370 \mathrm{~Bq} / \mathrm{kg}$ \\
Absorbed Dose rate $(\mathrm{D}) \mathrm{nGy} \cdot \mathrm{h}^{-1}$ & 51.296 & 202.800 & 13.900 & $57 \mathrm{nGyh}^{-1}$ \\
Annual Effective Dose $(\mathrm{E}) \mathrm{mSv} \cdot \mathrm{y}^{-1}$ & 0.062 & 0.240 & 0.017 & $1 \mathrm{mSv} / \mathrm{yr}$. \\
External Radiation Hazard Index $\left(\mathrm{H}_{\mathrm{ex}}\right)$ & 0.309 & 1.230 & 0.080 & 1 \\
Criteria formula $(\mathrm{CF})$ & 0.154 & 0.600 & 0.040 & 1 \\
Gamma radiation hazard index & 0.806 & 3.194 & 0.222 & 1 \\
Excess lifetime cancer risk & 0.235 & 0.932 & 0.063 & 0.290 \\
Annual Gonadal equivalent dose $\left(\mu \mathrm{Sv} \cdot \mathrm{y}^{-1}\right)$ & 347.878 & 1365.208 & 96.366 & 600 \\
Activity Utilization Index & 0.949 & 3.869 & 0.206 & 2 \\
\hline
\end{tabular}

province of Sri Lanka hadan external radiation hazard index greater than 1 . The median external hazardous index was 6.0 varying from 3.3 to 8.3 (Warnakulasuriya et al., 2020). The indoor dose rates of the sampling sites were not evaluated as essential data on the average buildup of radon in the indoor atmosphere were not available.

The median CF value (Criteria Formula) for the soil samples of Norochcholai was 0.15 (Table 2) which was below the recommended maximum value of 1 . Hence, the soil in this area can be safely used construction of dwellings. A recent study in some areas of Tamil Nadu, India reported that the soil had a Criteria Formula value of 0.202 which was below the recommended limit of one (Raghu, Harikrishnan, Chandrasekaran, Govardhanan, \& Ravisankar, 2015). Hewamanna et al. reported that the CF value of Sri Lankan clay bricks used in building construction (in all 25 districts) varied between 0.07 and 0.49 , posing no radiological hazard (Hewamanna, Sumithrarachchi, Mahawatte, Nanayakkara, \& Ratnayake, 2001).

The gamma radiation hazards index (Gamma representative index) determines the level of gamma radiation associated with the measured activity concentrations of the primordial nuclides. The recommended value should be less than one (UNSCEAR, 2000). The median gamma representative index in Norochcholai area was 0.548 , the value being less than the recommended level. In Pulmoddai, Sri Lanka, the median gamma representative index was 15.3, much higher than the recommended limit (Warnakulasuriya et al., 2020). In the vicinity of the Al-Dura thermal power plant in the south of Baghdad, Iraq, the natural radioactivity of fly ash released from the plant had a representative gamma index (I $\gamma$ ) of about 1.037, which was slightly higher than the global average (Ahmed, Jasim, \& Shafik, 2016).

The world average value for excess lifetime cancer risk (ELCR) is 0.290 (Tufail, Akhtar, Jaried, \& Hamid, 2007). The median ELCR in Norochcholai was 
0.232 , below the recommended limit. ELCR determines the possibility of an individual exposed to ionizing radiation developing cancer or being diagnosed with cancer during their lifetime. In some areas of the eastern part of Sri Lanka the median ELCR varied between 0.2 and 4.4 (Warnakulasuriya et al., 2020), exceeding the safety limit. The ELCR in some regions of the Southwestern part of Nigeria ranged from 0.46 to 1.17 (mean $=0.635)$.

The Annual Gonadal Equivalent Dose (AGED) can be used as an index of radiation exposure to the gonads as the gonads are necessary organs that can be affected by exposure to radiation. AGED (Annual Gonadal equivalent dose) varied from $96.37 \mu \mathrm{Sv} \cdot \mathrm{y}^{-1}$ to $1365.21 \mu \mathrm{Sv} \cdot \mathrm{y}^{-1}$ with a mean of $452.6 \mu \mathrm{Sv} \cdot \mathrm{y}^{-1}$ which was below the permissible level. Only four samples from Norochcholai exceeded the world recommended limit of $600 \mu \mathrm{Sv} \cdot \mathrm{y}^{-1}$. Increased levels of AGED can cause leukemia (UNSCEAR, 1988). Warnakulasuriya et al. (2020) recently reported that the AGED in the Pulmoddai area located in the eastern part of Sri Lanka varied between $3605.3 \mu \mathrm{Sv} \cdot \mathrm{y}^{-1}$ and $9078.1 \mu \mathrm{Sv} \cdot \mathrm{y}^{-1}$. This was much higher than the world recommended limit of $600 \mu \mathrm{Sv} \cdot \mathrm{y}^{-1}$. In Kerala, India, AGED ranged from 0.14 to $66.15 \mathrm{mSv} \cdot \mathrm{y}^{-1}$ (Thomas, Vijayagopal, Balasubramanium, Chaubey, \& Kumar, 2012). More than 90 towns and cities of Iran had an AGED of $0.24 \mathrm{mSv} \cdot \mathrm{y}^{-1}$ much higher than the world permissible limit (Toossi et al., 2009).

An Activity Utilization Index (AUI) $<2$ is equivalent to an annual effective dose of $<0.3 \mathrm{mSv} / \mathrm{y}$ which is safe for the environment. AUI is the parametric mode that enables one to determine radionuclide dose levels in the air from the soil samples (Sivakumar et al., 2014). The median AUI in Norochcholai was 0.9 which was below the recommended safe limit of 2 .

\section{Conclusion}

In Norochcholai, radioactivity concentrations of all radionuclides except ${ }^{232} \mathrm{Th}$ were lower than the world's average. Radium equivalent activity, annual effective dose, criteria formula, absorbed dose rate, annual gonadal equivalent dose, excess life time cancer risk, and activity utilization index are well below the recommended limits. Therefore, soil in this area can be safely used as building material for construction of dwellings. The indoor dose rates of the sampling positions were not evaluated. Soil sample data could not express the contribution of radon whereas survey meter data gives a measure regarding total background radiation. Because there were no essential data available on the average buildup of radon in the indoor atmosphere. The results of the study confirm that radiation exposure and associated dose rates are well below the permissible levels.

The external hazard index for all the soil samples was lower than unity which indicates that the soil from this study area poses a minimal risk to human health. Previously, no works on this area for measurements of radioactivity was carried out. Therefore, these data could be used as baseline data for radiation assess- 
ments and further research work in the area.

\section{Author Contributions}

Thiwanka Weerakkody: Writing original draft, Conceptualization, Methodology. Senani Williams: Supervision, Reviewing and Editing. Tania Warnakulasuriya: Analysis of data. Shakila Priyadarshanee: Drawing maps. Thilaka Attanayaka: Methodology. Indrani Dissanayake: Methodology. Vajira Waduge: Reviewing and Editing. Rajitha Wickremasinghe: Supervision, Reviewing and Editing, Final approval of the version to be published.

\section{Acknowledgements}

The authors are thankful to the residents of the study area for their cooperation during the fieldwork and a special thank goes to Mr. Dakshina Hettiarachchi for his support in sampling activities.

\section{Funding}

This work was supported by the National Research Council, Sri Lanka (grant number 13-033).

\section{Conflicts of Interest}

The authors declare no conflict of interest.

\section{References}

Ahmed, I. K., Jasim, M. H., \& Shafik, S. S. (2016). The Concentrations of Natural Radioactivity in Fly Ash Released from Al-Dura Thermal Power Plant in the South of Baghdad City. Iraqi Journal of Science, 57, 1192-1197.

Atomic Energy Authority (1988). Preliminary Report on Safety Aspects of Nuclear Power Generation in Sri Lanka.

Bandara, W., \& Mahawatte, P. (2015). Radioactivity Levels in Beach Sand from Hambantota to Dondra, Sri Lanka. In Proceedings of 8th International Research Conference (pp. 30-35).

Bavarnegin, E., Moghaddam, M. V., \& Fathabadi, N. (2013). Natural Radionuclide and Radiological Assessment of Building Materials in High Background Radiation Areas of Ramsar, Iran. Journal of Medical Physics, 38, 93-97. https://doi.org/10.4103/0971-6203.111325

Bozkurt, A., Yorulmaz, N., Kam, E., Karahan, G., \& Osmanlioglu, A. (2007). Assessment of Environmental Radioactivity for Sanliurfa Region of Southeastern Turkey. Radiation Measurements, 42, 1387-1391. https://doi.org/10.1016/i.radmeas.2007.05.052

Cousins, C., Boice Jr., J., Cooper, U. J., Lee, U.J., \& Lochard, K. J. (2018). Annals of the ICRP Published on Behalf of the International Commission on Radiological Protection International Commission on Radiological Protection Members of the 2010-2013 Main Commission of ICRP. http://journals.sagepub.com/doi/pdf/10.1177/ANIB 37 2-4

Department of Census and Statistics, Sri Lanka (2012).

Dhawal, S. J., Kulkarni, G. S., \& Pawar, S. H. (2013). Terrestrial Background Radiation Studies in South Konkan, Maharashtra, India. International Journal of Radiation Re- 
search, 11, 263-270.

European Commission (1999). Radiation Protection 112-Radiological Protection Principles Concerning the Natural Radioactivity of Building Materials Directorate-General Environment. European Commission.

Florou, H., \& Kritidis, P. (1992). Gamma Radiation Measurements and Dose Rate in the Coastal Areas of a Volcanic Island, Aegean Sea, Greece. Radiation Protection Dosimetry, 45, 277-279. https://doi.org/10.1093/rpd/45.1-4.277

Hewamanna, R., Sumithrarachchi, C. S., Mahawatte, P., Nanayakkara, H. L., \& Ratnayake, H. C. (2001). Natural Radioactivity and Gamma Dose from Sri Lankan Clay Bricks Used in Building construction. Applied Radiation and Isotopes, 54, 365-369. https://doi.org/10.1016/S0969-8043(00)00107-X

IAEA (International Atomic Energy Agency) (1989). Measurement of Radionuclides. International Atomic Energy Agency.

IAEA (International Atomic Energy Agency) (2015). General Safety Requirements No. GSR Part 7, IAEA Safety Standards, Preparedness and Response for a Nuclear or Radiological Emergency. International Atomic Energy Agency.

ICRP (International Commission on Radiological Protection) (1977). Recommendations of the ICRP. Pergamon Press.

Krieger, R. (1981). Radioactivity of Construction Materials. Betonnwerk Fertigteil Technology, 47, 468-473.

Lu, X., \& Zhang, X. (2006). Measurement of Natural Radioactivity in Sand Samples Collected from the Booje Weihe Sand Park, China. Environmental Geology, 50, 977-982. https://doi.org/10.1007/s00254-006-0266-5

Mahawatte, P., \& Fernando, K. N. (2013). Radioactivity Levels in Beach Sand from the West Coast of Sri Lanka. Journal of National Science Foundation Sri Lanka, 41, 279-285. https://doi.org/10.4038/jnsfsr.v41i4.6249

Malanca, A., Gaidolfi, L., Pessina, V., \& Dallara, G. (1996). Distribution of ${ }^{226} \mathrm{Ra},{ }^{232} \mathrm{Th}$, and ${ }^{40} \mathrm{~K}$ in Soils of Rio Grande do Norte (Brazil). Journal of Environmental Radioactivity, 30, 55-67. https://doi.org/10.1016/0265-931X(95)00035-9

Miah, A., Miah, M., Kamal, M., Chowdhury, M., \& Rahmatullah, M. (2012). Natural Radioactivity and Associated Dose Rates in Soil Samples of Malnichera Tea Garden in Sylhet District of Bangladesh. Journal of Nuclear and Particle Physics, 2, 147-152. https://doi.org/10.5923/j.jnpp.20120206.03

Ndontchueng, M. M., Nguelem, E. J., Simo, A., Njinga, R. L., \& Joël, G. S. (2014). Gamma Emitting Radionuclides in Soils from Selected Areas in Douala-Bassa Zone, Littoral Region of Cameroon. International Scholarly Research Notices, 2014, Article ID: 245125. https://doi.org/10.1155/2014/245125

NEA (Nuclear Energy Agency) (1979). Exposure to Radiation from Natural Radioactivity in Building Material. Nuclear Energy Agency, NEA group of Experts.

Raghu, Y., Harikrishnan, N., Chandrasekaran, A., Govardhanan, B., \& Ravisankar, R. (2015). FFA Study on Activity Concentration of Natural Radionuclides of Building Materials in Pachal, Tiruvannamalai Dist, Tamilnadu, India. Journal of Environment and Health Sciences, 1, 1-5. https://doi.org/10.15436/2378-6841.15.004

Rani, A., \& Singh, S. (2005). Natural Radioactivity Levels in Soil Samples from Some Areas of Himachal Pradesh India Using $\gamma$-Ray Spectrometry. Atmospheric Environment, 39, 1606-1634. https://doi.org/10.1016/j.atmosenv.2005.07.050

Sivakumar, S., Chandrasekaranb, A., Ravisankar, R., Ravikumar, S., Prince, M. J., Prakash, J. et al. (2014). Measurement of Natural Radioactivity and Evaluation of Radia- 
tion Hazards in Coastal Sediments of East Coast of Tamilnadu using statistical approach. Journal of Taibah University for Science, 8, 375-384.

https://doi.org/10.1016/j.jtusci.2014.03.004

Subramanian, S., Jeyapandian, M., Brahmanandhan, G. M., \& Khanna, D. (2009). Background Radiation Dose to the Population around the Kudankulam Nuclear Power Plant. In M. Nakashima, N. Takamura, K. Tsukasaki, Y. Nagayama, \& S. Yamashita (Eds.), Radiation Health Risk Sciences (248-253). Springer.

https://doi.org/10.1007/978-4-431-88659-4 32

Thomas, D., Vijayagopal, P., Balasubramanium, V., Chaubey, R. C., \& Kumar, G. A. (2012). Radionuclides and Radiation Indices of High Background Radiation Area in Chavara-Neendakara Placer Deposits (Kerala, India). PLoS ONE, 7, Article ID: e50468. https://doi.org/10.1371/journal.pone.0050468

Toossi, M. T., Bayani, S. H., Yarahmadi, M., Aghamir, A., Jomehzadeh, A., Parast, P. H., \& Tamjidi, A. (2009). Gonad, Bone Marrow and Effective Dose to the Population of More than 90 Towns and Cities of Iran, Arising from Environmental Gamma Radiation. Iran Journal of Radiation Research, 7, 41-47.

Tufail, M., Akhtar, N., Jaried, S., \& Hamid, T. (2007). Natural Radioactivity Hazards of Building Bricks Fabrication from Soil of Two Districts of Pakistan. Journal of Radiological Protection, 27, 481-492. https://doi.org/10.1088/0952-4746/27/4/009

Tzortzis, M., Svoukis, E., \& Tsertos, H. (2001). A Comprehensive Study of Natural Gamma Radioactivity Levels and Associated Dose Rates from Surface Soils in Cyprus. Radiation Protection Dosimetry, 109, 217-224. https://doi.org/10.1093/rpd/nch300

UNSCEAR (United Nations Scientific Committee on the Effects of Atomic Radiation) (1988). Sources, Effects and Risk of Ionizing Radiation. United Nations.

UNSCEAR (United Nations Scientific Committee on the Effects of Atomic Radiation) (2000). Annex B: Exposures from Natural Radiation Sources.

UNSCEAR (United Nations Scientific Committee on the Effects of Atomic Radiation) (2012). Sources, Effects and Risk of Ionizing Radiation. Report to the General assembly, with Scientific Annexes ( $A$ and $B$ ). United Nations.

Vasconcelos, D. C., Pereira, C., Oliveira, A. H., Santos, T. O., Reis, P. L., \& Rocha, Z. (2011). Natural Radioactivity in Sand Beaches of Guarapari Espirito Santo State, Brazil-A Comparative Study. In International Nuclear Atlantic Conferance-INAC.

Warnakulasuriya, T., Williams, S., Weerakkody, T., Dabarera, M., Rodrigo, K., Waduge, V. et al. (2020). Background Radiation Levels Near a Mineral Sand Mining Factory in Sri Lanka: Correlation of Radiation Measurements with Micronuclei Frequency. Radiation Protection Dosimetry, 189, 114-126. https://doi.org/10.1093/rpd/ncaa022

Wesley, S. G. (2012). Kudankulam Environment: Baseline Studies (Before Startup Nuclear Power Station). Print Point Offset Press.

Withanage, A. P., \& Mahawatte, P. (2013). Radioactivity of Beach Sand in the Southwestern Coast of Sri Lanka. Radiation Protection Dosimetry, 153, 384-389. https://doi.org/10.1093/rpd/ncs107

Al-Kaabi, M. A., \& Al-Shimary, A. (2015, November 30). Study of the Radiological Doses and Hazard Indices in Soil Samples from Karbala City, Iraq (pp. 1-9).

Sri Lanka Atomic Energy Board (2018, January 15). Baseline Radioactivity Data. https://aeb.gov.lk/web/index.php?option=com content\&view=article\&id=333\&Itemid =255\&lang=en 